\title{
Spatio-temporal occurrence patterns among the foreshocks preceding the 2007 Noto Hanto earthquake
}

\author{
Issei Doi* and Hironori Kawakata \\ College of Science and Engineering, Ritsumeikan University, Noji-higashi, Kusatsu, Shiga 525-8577, Japan
}

(Received December 20, 2012; Revised April 2, 2013; Accepted April 2, 2013; Online published October 9, 2013)

\begin{abstract}
The 2007 Noto Hanto earthquake was a magnitude 6.8 crustal earthquake (Japan Metrological Agency) that occurred in central Japan. By analyzing continuous seismograms that recorded activity during the 25 days before the earthquake, we detected 36 small seismic events around the mainshock hypocenter that classified as either isolated events or members of three clusters. Three of the detected events are listed in official seismic records. Two clusters included more than ten events and occurred some distance from the mainshock fault, indicating that the clusters did not relate to the mainshock event. Only the third cluster was located along the mainshock fault. This cluster occurred in the vicinity of the mainshock hypocenter and consisted of four foreshocks with identical seismograms. This cluster began twelve minutes before the mainshock. The occurrence pattern of this clustered foreshock sequence is similar to that observed in association with the 2008 Iwate-Miyagi Inland earthquake.
\end{abstract}

Key words: Foreshocks, crustal earthquake, cluster, quiescence, correlation analysis.

\section{Introduction}

Foreshocks provide a means by which to study smallscale failure processes that precede much larger events. Rock failure experiments have shown that acoustic emissions (AEs) occur prior to major failure (e.g. Scholz, 1968; Lockner et al., 1992). Empirical studies using hypocentral catalog information have also identified important characteristics that are common among foreshocks. Dodge et al. (1996), for example, found that foreshocks occurred during the nucleation phase of the mainshock. Jones and Molnar (1979) proposed the so-called inverse Omori law for the accelerative sequence of the foreshock behavior.

Recent analyses of data recorded by a dense seismic observation network have shown that smaller seismic events (those previously unrecorded by official catalogs) can provide new insights into foreshock patterns. Clustered foreshocks having identical seismograms occurred adjacent to the mainshock hypocenter for both the 1999 Izmit interplate earthquake in Turkey (Bouchon et al., 2011) and the 2008 Iwate-Miyagi Inland crustal earthquake in Japan (Doi and Kawakata, 2012). Bouchon et al. (2011) identified 40 small foreshocks preceding the Izmit interplate earthquake. These foreshocks abruptly began 44 minutes before the mainshock and increased in frequency as the time of the mainshock event approached. Doi and Kawakata (2012) identified 22 small foreshocks preceding the Iwate-Miyagi Inland crustal earthquake. These foreshocks also abruptly began $42 \mathrm{~min}-$

\footnotetext{
*Now at Disaster Prevention Research Institute, Kyoto University, Uji, Kyoto 611-0011, Japan.

Copyright (c) The Society of Geomagnetism and Earth, Planetary and Space Sciences (SGEPSS); The Seismological Society of Japan; The Volcanological Society of Japan; The Geodetic Society of Japan; The Japanese Society for Planetary Sciences; TERRAPUB
}

doi:10.5047/eps.2013.04.001 utes before the mainshock but their frequency remained constant, and a 10-minute period of quiescence preceded the mainshock. Both of these studies focused only on seismic activity in the same general region of the mainshock rupture initiation points. Additional study of large earthquakes and seismic activity in the surrounding area can further elucidate factors that influence foreshock occurrence patterns.

This study seeks to clarify the consistency with which large earthquakes are accompanied by clustered foreshocks, and to determine whether other foreshocks may have occurred within the total mainshock rupture volume. The 2007 Noto Hanto earthquake, with a JMA magnitude $\left(M_{\mathrm{j}}\right.$; Japan Metrological Agency) of 6.8, allowed us to estimate the spatio-temporal patterns in seismic activity throughout its source region.

\section{The 2007 Noto Hanto Earthquake}

The 2007 Noto Hanto earthquake occurred in central Japan at 9:41 on March 25, 2007 (LT). The earthquake was classified as a crustal earthquake and had a focal depth of $10.7 \mathrm{~km}$ according to the JMA catalog. Observations of the dense temporary aftershock array (Sakai et al., 2008) revealed an ENE trending mainshock fault dipping 50-60 to the SSE. According to inversion analyses of seismic and geodetic data (e.g. Fukushima et al., 2008; Horikawa, 2008), the area of dominant slip produced by the mainshock was $20-\mathrm{km}$ in length for both strike and dip directions. The mainshock had an initial phase corresponding to a $M_{\mathrm{j}} 4.4$ precursor event, which occurred $0.6 \mathrm{~s}$ before the mainshock at a distance of $1.2 \mathrm{~km} \mathrm{WSW}$ of the epicenter (Sakai et al., 2008). The official JMA hypocentral catalog recorded three seismic events within a $20 \mathrm{~km}$ radius of the mainshock hypocenter during the 25 days preceding the mainshock. 


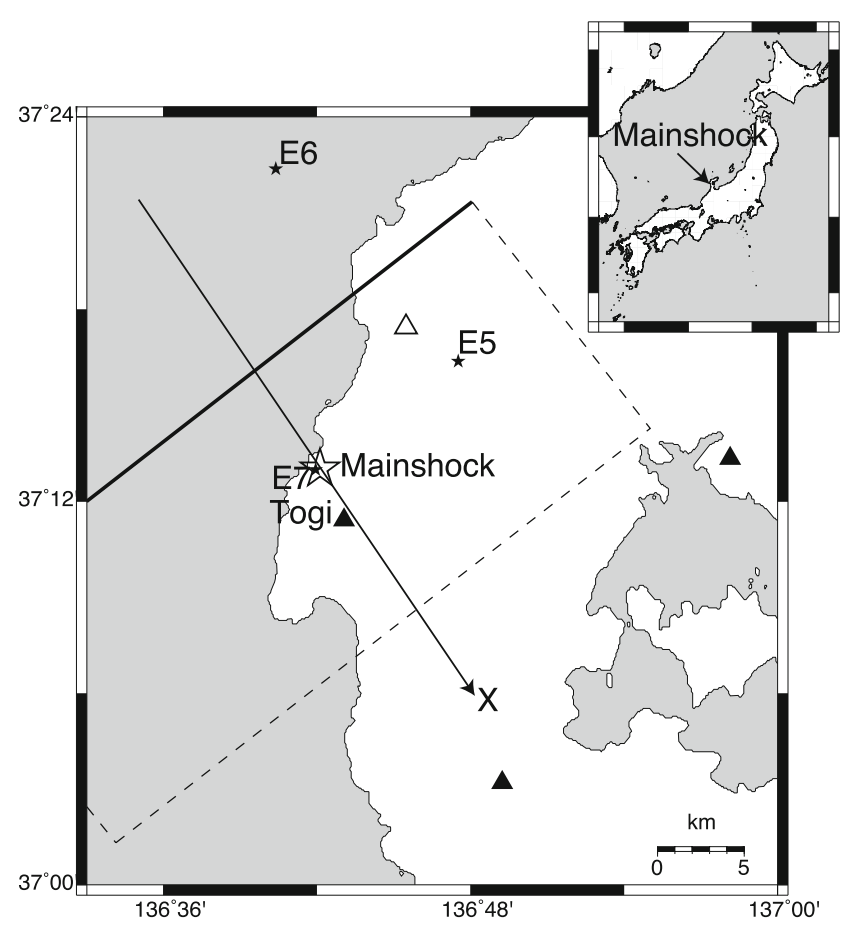

Fig. 1. A map showing the hypocenters of the mainshock (open star) and smaller seismic events (solid stars) cataloged in association with the 2007 Noto Hanto earthquake. Triangles denote the locations of the Hi-net stations. The open triangle marks a station that was non-operational during the mainshock event. The square represents the fault plane assumed in the source inversion analysis by Fukushima et al. (2008).

\section{Detection of Small Seismic Events around the Mainshock Hypocenter}

\subsection{Data}

We used continuous seismograms recorded by the Togi seismic station of the High Sensitivity Seismograph Network Japan (Hi-net). This station is the only one situated in the source region of the mainshock, located within a 5$\mathrm{km}$ epicentral distance (Fig. 1). The data collection period spanned about 25 days from 0:00 on 1 March to 9:45 on 25 March, 2007. Continuous seismograms recorded seismic activity with a $0.01 \mathrm{~s}$ sampling interval at 27 bit resolution.

\subsection{Detection of reference seismic events with distinct seismograms}

Seismic signals are non-stationary signals with a broad frequency content. Using these properties, we analyzed the continuous seismograms with the following two automated methods in order to detect candidate reference seismic events, especially those not listed in the JMA catalog.

First, we calculated running spectra of the up-down component for seismograms at two-second intervals. Because spectral amplitudes for continuous seismic signals accumulate signal power in the $1-40 \mathrm{~Hz}$ frequency band, candidate time windows for seismic events were according to a signal to background-noise ratios threshold of $>2.0$ for both $15-25 \mathrm{~Hz}$ and $25-35 \mathrm{~Hz}$ frequency bands. We did not use the $1-10 \mathrm{~Hz}$ frequency band due to high levels of ambient noise therein. These selection procedures yielded 12,632 candidate events.

Next, we examined whether the candidate events were earthquakes using values of the Akaike Information Criterion (AIC) with which $P$-wave onset can be recognized (Takanami and Kitagawa, 2002). We set a time window starting two seconds before, and lasting until two seconds after, the candidate time windows. If the minimum of AIC values was beyond three times the standard deviation, we judged that the candidate time window included the seismic signals. This process reduced the number of candidate events down to 46.

Candidate events that are likely to include the seismic signals were then visually checked along with their two horizontal components. Given the areal extent of the mainshock source region, we selected seismograms with $S-P$ times less than $3.0 \mathrm{~s}$. These screening steps ultimately yielded nine reference seismic events, referred to in chronological order as E1 to E9. These events include each of the three events listed in the JMA catalog as occurring near the source region of the mainshock. The seismograms for each of these seismic events are shown in Fig. 2.

\subsection{Clustered seismicity around the mainshock}

Smaller seismic events with lower $\mathrm{S} / \mathrm{N}$ ratios may go undetected by the procedures described in the previous section. The correlation method described below provides a powerful alternative means by which to identify smaller events (e.g. Bouchon et al., 2011).

The reference events used to constellate event clusters were selected as follows. We calculated the crosscorrelation function for each combination of the seismogram segments belonging to the E1 through E9 events. The seismograms for E3, E4, E5, and E6 did not exhibit high cross-correlation coefficients with any seismogram from other events and could thus serve as reference events. The maximum value of the normalized cross-correlation function between E1 and E2 reached 0.8. The E7, E8, and E9 seismograms exhibited relatively high cross-correlation coefficients $(>0.6)$ with one another. The larger events provide the best reference points due to their likelihood of hav- 
Up-down component

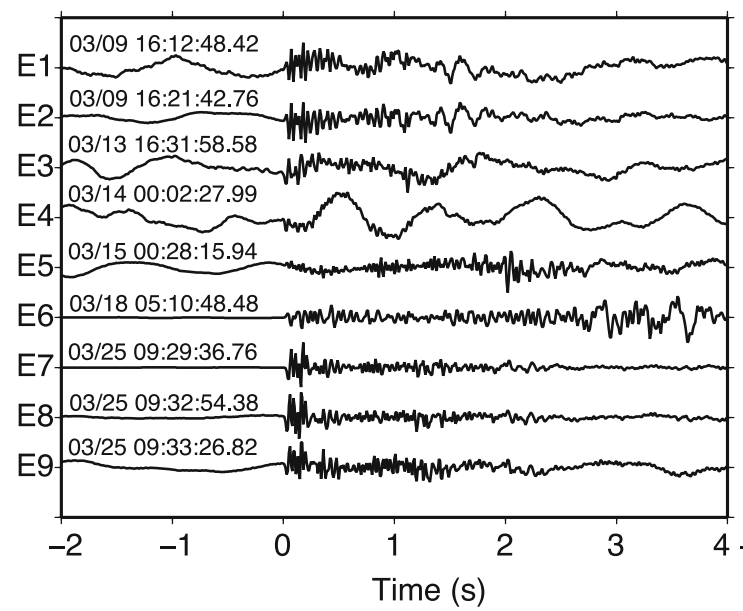

East-west component

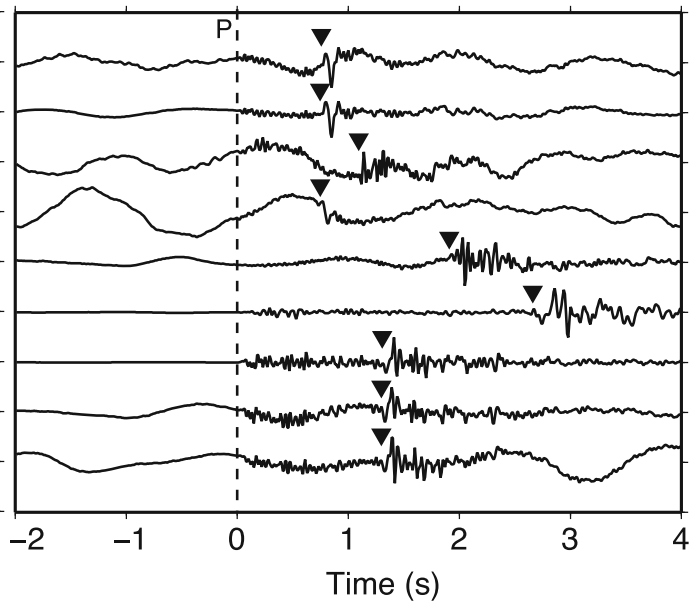

Fig. 2. Unprocessed seismograms for the updown (left panel) and east-west (right panel) components of the E1 through E9 reference events. Seismograms are normalized by their maximum amplitude. The $P$ - and $S$-phase onsets are shown by a dashed line and inverted triangles, respectively.

Table 1. Time windows used for correlation analysis, the number of cluster events, and $S$ - $P$ times estimated from the Togi seismic station for E2, E3, E4, E5, E6, and E8. Parentheses denote the numbers of the members in the cluster when events whose cross-correlation coefficients were higher for other clusters are excluded. Note that the E2 cluster includes E1 while E7 and E9 belong to the E8 cluster.

\begin{tabular}{ccccc}
\hline ID & Time window before $P(\mathrm{~s})$ & Time window after $P(\mathrm{~s})$ & N. of EQ & $S$ - $P$ time (s) at Togi \\
\hline E2 & 0.6 & 1.5 & $18(16)$ & 0.77 \\
E3 & 0.8 & 2.5 & 2 & 1.11 \\
E4 & 0.6 & 1.5 & $13(12)$ & 0.71 \\
E5 & 1.0 & 3.5 & 1 & 1.95 \\
E6 & 1.5 & 4.5 & 1 & 2.81 \\
E8 & 0.8 & 2.5 & 4 & 1.30 \\
\hline
\end{tabular}

ing high $\mathrm{S} / \mathrm{N}$ ratios. Although $\mathrm{E} 7$ was the largest event in the subset, we did not use it as a reference because its magnitude $\left(M_{\mathrm{j}} 2.0\right)$ was so large that its duration may exceed the period of the bandpass filter applied to the data. We therefore only used the E2, E3, E4, E5, E6, and E8 events as references.

We identified matching seismogram segments for each selected reference event. Detection of smaller seismic events required the following two steps in order to avoid overly intensive computational operations (Doi and Kawakata, 2012). We first calculated cross-correlation coefficient time series between a subset of $15-40 \mathrm{~Hz}$ bandpass-filtered continuous seismograms covering a series of overlapping time windows and the reference event seismogram. This procedure identified candidate events grouped among several clusters (e.g. Gibbons and Ringdal, 2006). The durations of the overlapping time windows used to calculate correlation coefficients (Table 1) were selected to include both $P$ - and $S$-phases. We selected candidate seismograms for which cross-correlation coefficients averaged among the three components (i.e. updown and two horizontal) were larger than three times their respective standard deviations. The candidate seismograms were then interpolated to a $1,000-\mathrm{Hz}$ sampling frequency in order to retain smaller phase shifts that may have gone undetected by the initial sampling interval. Following interpolation, cross-correlation coefficients between reference and candidate seismograms were re-calculated using overlapping time windows to determine their maximum values.

Figure 3 shows maximum cross-correlation coefficient time series for candidate seismograms. We considered seismograms to represent clustered events when their maximum cross-correlation coefficients exceeded values of 0.6. Table 1 lists the number of potential cluster members of foreshocks for each reference event. The E3, E5, and E6 events had no more than one associated event (in addition to the reference event itself). The E2 and E4 events showed more than 10 events within their clusters with cross-correlation coefficients greater than 0.6 , most of which occurred mainly 11 and 16 days before the mainshock. The E8 cluster showed four events during the 8-12 minutes leading up to the mainshock including E7 and E9. All in all, we detected three examples of clustered seismicity.

\subsection{Hypocenter locations and mechanisms of the clus- tered seismic events}

The signals of most events detected in the previous sections were recognized only at Togi station. The relative hypocenter locations within each cluster to the reference events were estimated from $S-P$ time differences. A correlation method using overlapping time windows was separately applied to $P$ - and $S$-phases in the interpolated seismograms for each cluster. We used interpolated seismograms for reference events (E2, E4, and E8) with a duration of $0.6 \mathrm{~s}$, starting $0.05 \mathrm{~s}$ before the onsets of the respective $P$ - and $S$-phases. The $S$ - $P$ times of each event in a given cluster differed by only $0.003 \mathrm{~s}$ indicating that the hypocen- 

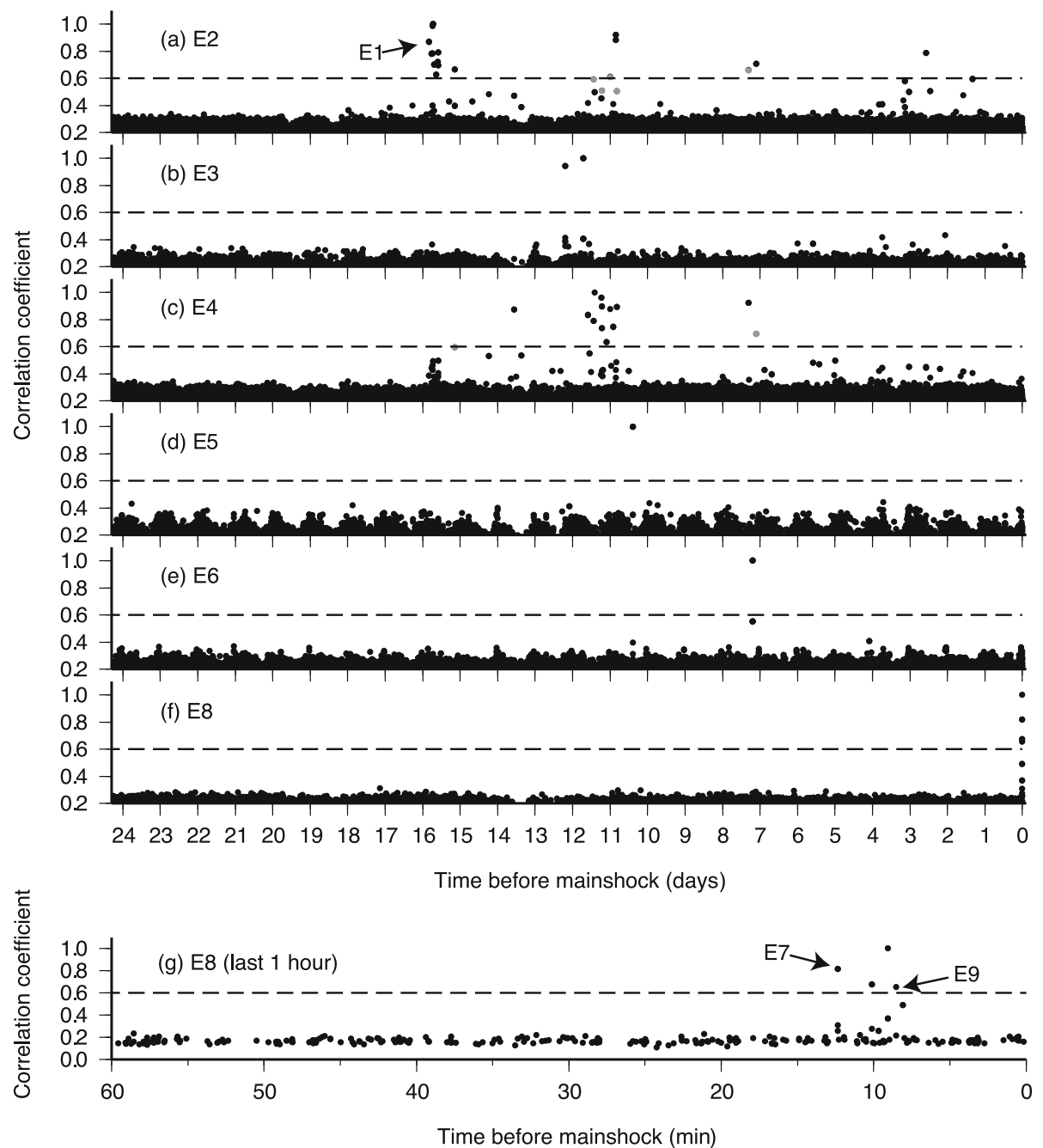

Fig. 3. Time series of cross-correlation coefficients averaged among the three components for the reference events (a) E2, (b) E3, (c) E4, (d) E5, (e) E6, and (f) E8 during the 25-day period leading up to the mainshock. The bottom panel (g) represents a segment of (f) magnified for the last hour prior to the mainshock. The dashed lines denote the correlation threshold of 0.6. Gray circles denote events whose cross-correlation coefficients are higher for other clusters.

ters of the events in each cluster were located within a 20 $\mathrm{m}$ radius of each other. This analysis also showed that the hypocenters of E7, E8, and E9 as well as the E1 and E2 hypocenters were all located at similarly proximal distances.

We referred to the JMA hypocentral catalogs and Sakai et al. (2008) for the absolute hypocenter locations of each of the reference seismic events. These sources listed earthquakes that corresponded to the E5, E6, and E7 events. Figures 1 and 4 show the epicenter and hypocenter locations of these earthquakes. The E6 event occurred at a relatively large distance from the mainshock rupture surface inferred from the aftershock distribution (shown as the solid gray ellipse in Fig. 4). By contrast, the E5 and E7 events (as well as the E8 and E9 events) occurred near the rupture surface. The E5 event occurred at an estimated distance of no more than $10 \mathrm{~km}$ from the mainshock hypocenter, whereas E7 occurred immediately adjacent to the mainshock hypocenter.

We also estimated the hypocenter location and the mechanism of the E7 hypocenter relative to the mainshock from the relative $P$-arrival times and $P$-wave polarities recorded at ten local seismic stations in the general Togi area. The relative arrival times (transformed to root-mean-square values for comparison) calculated from visually estimated $P$ times differed only by $0.03 \mathrm{~s}$ for each station. The polarities for the initial $P$-waves were the same at all the stations, though ten stations were insufficient to completely constrain the mechanism solution. The mechanism of E7 was considered to be identical to that of the initial rupture of the mainshock. These facts indicate that E7 occurred within a 200-m radius of the mainshock and on the fault plane of the mainshock initial rupture (strike slip type estimated by Kato et al., 2011). Each of the four events included in the E7, E8, and E9 cluster, in fact, occurred within a 200$m$ radius of the mainshock's rupture initiation point from the high cross-correlation coefficients among their seismograms.

The $P$ - and $S$-phases associated with the E1, E2, E3, and E4 events could not be detected in continuous seismograms other than that recorded at the Togi station. The $S-P$ times for E2 (and E1) and E4 of 0.7-0.8 s (see Fig. 2 and Table 1) indicate that the hypocentral distances between these events and the Togi station were around $5 \mathrm{~km}$, according to empirical relationship by Omori (1899). Figure 4 shows 


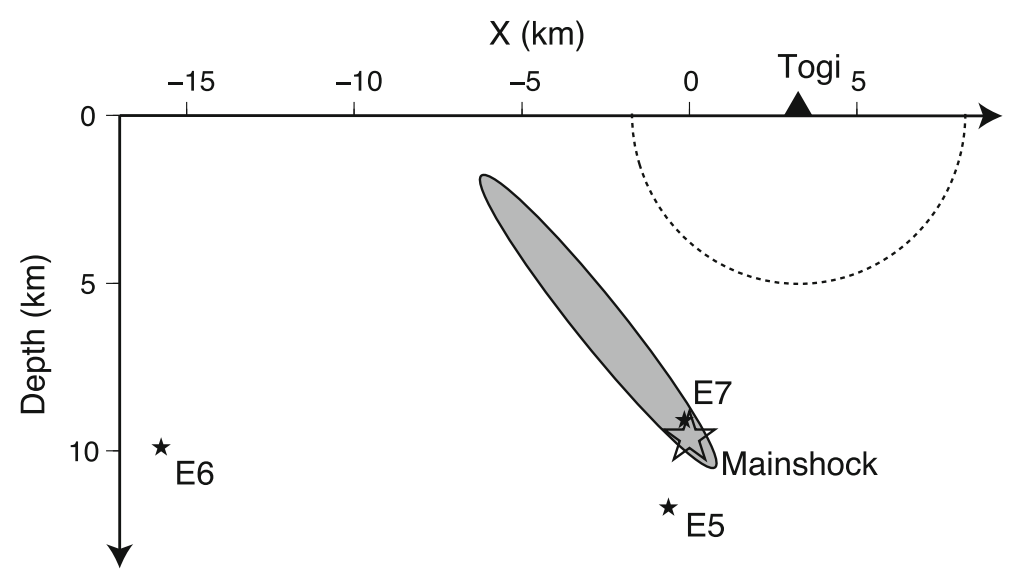

Fig. 4. The distribution of the mainshock (open star) and associated seismic events (solid stars) from the reference catalog projected onto the $X$-axis shown in Fig. 1. The solid ellipse denotes aftershock distributions along the mainshock fault (Sakai et al., 2008). The solid triangle shows the location of the Togi seismic station. The dashed semicircle represents the area within which the hypocenters of E2 and E4 should be located.

a semicircle with a radius of $5 \mathrm{~km}$ marking the area within which E2 and E4 hypocenters likely occurred. Travel times indicate that E2 and E4 did not occur along the mainshock fault plane. The E3 event may have occurred near the rupture plane according to its $S$ - $P$ time $(1.1 \mathrm{~s})$ as recorded by the Togi station.

\section{Relationship between Clustered Foreshocks and the Mainshock}

Clustered foreshocks occurred in the same general area as the mainshock hypocenter for both the 1999 Izmit earthquake (Bouchon et al., 2011) and the 2008 Iwate-Miyagi Inland earthquake (Doi and Kawakata, 2012). Clustered seismic events referred to here as E7, E8, and E9 also occurred in close proximity to the rupture initiation point for the mainshock of the 2007 Noto Hanto earthquake. The four clustered seismic events described here are similar to those described in previous studies but fewer in overall number. Foreshocks of interest in this study abruptly began 12 minutes before the mainshock.

The other two seismic clusters constellated around the E2 and E4 reference events and included more than 10 events that occurred primarily 11 and 16 days before the mainshock. Hypocenters for the events in these clusters were relatively distant from the mainshock fault plane. Magnitudes for the events in these clusters were relatively small. These lines of evidence indicate that the events do not relate to failure and nucleation associated with the mainshock. The isolated E3 and E5 events may have occurred near the mainshock fault but not in the vicinity of the rupture initiation point. The E3 and E5 events may, thus, represent a different type of foreshock and require further investigation.

The slip distributions in association with the mainshock rupture (Horikawa, 2008) showed that small slips were estimated around the initial rupture point of the mainshock. Also, not so many aftershocks occurred there (Sakai et al., 2008). These facts suggest that some amount of the strain energy had already been released prior to the mainshock and that the strength at this point decreased beforehand. In a rock failure experiment, AEs were observed in the nucleation region (Lockner et al., 1992) and a velocity de- crease was measured (Yoshimitsu et al., 2009) before the final fracture but after the peak stress, which suggested that yielding occur before the final fracture. The fact that foreshocks were detected adjacent to the initial rupture point of the later mainshock may be evidence that the yielding had started at least 12 minutes before the mainshock. Foreshocks adjacent to the initial rupture point of the mainshock were also observed for the 2008 Iwate-Miyagi Inland earthquake.

Experiments in laboratories have shown that precursory AEs occur before the main rupture (e.g. Scholz, 1968). However, it is not yet (and should be) clarified for application of the knowledge in laboratory experiments to natural fields whether natural earthquakes surely follow foreshocks. As shown in this study, continuous waveform records have a potential to find small foreshock (and other unrelated) activities that we would have missed in the catalog.

\section{Conclusions}

Careful examination of continuous seismograms revealed that 36 small seismic events occurred around the hypocenter of the 2007 Noto Hanto earthquake during the 25 days leading up to the mainshock event. Correlation analysis demonstrated that these seismic events clustered into three groups, or occurred as isolated events. Two clusters included more than ten events, the majority of which occurred in the two weeks before the mainshock. The relatively large distances between their hypocenters and the mainshock fault indicate that they do not relate to the mainshock event. On the contrary, the last cluster, which included four events, was located in the same general area as the rupture initiation point of the mainshock. Seismic activity in this foreshock cluster began twelve minutes before the mainshock but ceased for the last eight minutes. The spatio-temporal occurrence pattern of these foreshocks resembles that associated with the 2008 Iwate-Miyagi Inland earthquake. These findings demonstrate that clustered foreshocks occurring in close proximity to the mainshock hypocenter can potentially provide further information on the processes that generate larger catastrophic events. Dense permanent seismic networks in tectonically active areas are necessary to 
further analyze small seismic events occurring on or near mainshock faults, and distinguish them from unrelated seismic activity in the surrounding area.

Acknowledgments. We acknowledge the National Institute for Earthquake and Disaster Prevention for Hi-net operation and access to continuous seismograms recorded by Hi-net. We referred to the JMA catalog for earthquake hypocenter information. Chikara Asano, an undergraduate student at Ritsumeikan University, helped perform data analysis for this study. A lot of valuable comments from two anonymous reviewers helped us to improve our manuscript. The figures in this manuscript were drafted with General Mapping Tool (GMT) developed by Wessel and Smith (1998).

\section{References}

Bouchon, M., H. Karabulut, M. Aktar, S. Özalaybey, J. Schmittbuhl, and M.-P. Bouin, Extended nucleation of the 1999 Mw 7.6 Izmit Earthquake, Science, 331, 877-880, 2011.

Dodge, D. A., G. C. Beroza, and W. L. Ellsworth, Detailed observations of California foreshock sequences: Implications for the earthquake initiation process, J. Geophys. Res., 101, 22371-22392, 1996.

Doi, I. and H. Kawakata, A non-accelerating foreshock sequence followed by short quiescence for a large inland earthquake, Geophys. Res. Lett., 39, L11308, doi:10.1029/2012GL051779, 2012.

Fukushima, Y., T. Ozawa, and M. Hashimoto, Fault model of the 2007 Noto Hanto earthquake estimated from PALSAR radar interferometry and GPS data, Earth Planets Space, 60, 99-104, 2008.

Gibbons, S. J. and F. Ringdal, The detection of low magnitude seismic events using array-based waveform correlation, Geophys. J. Int., 165, 149-166, 2006.

Horikawa, H., Characterization of the 2007 Noto Hanto, Japan, earthquake, Earth Planets Space, 60, 1017-1022, 2008.

Jones, L. M. and P. Molnar, Some characteristics of foreshocks and their possible relationship to earthquake prediction and premonitory slip on faults, J. Geophys. Res., 84, 3596-3608, 1979.
Kato, A., S. Sakai, T. Iidaka, T. Iwasaki, E. Kurashimo, T. Igarashi, N. Hirata, T. Kanazawa, K. Katsumata, H. Takahashi, R. Honda, T. Maeda, M. Ichiyanagi, T. Yamaguchi, M. Kosuga, T. Okada, J. Nakajima, S, Hori, T. Nakayama, A. Hasegawa, T. Kono, S. Suzuki, N. Tsumura, Y. Hiramatsu, K. Sugaya, A. Hayashi, T. Hirose, A. Sawada, K. Tanaka, Y. Yamanaka, H. Nakamichi, T. Okuda, Y. Iio, K. Nishigami, M. Miyazawa, H. Wada, N. Hirano, H. Katao, S. Ohmi, K. Ito, I. Doi, S. Noda, S. Matsumoto, T. Matsushima, A. Saiga, H. Miyamachi, K. Imanishi, T. Takeda, Y. Asano, Y. Yukutake, T. Ueno, T. Maeda T. Matsuzawa, S. Sekine, M. Matsubara, and K. Obara, Anomalous depth dependency of the stress field in the 2007 Noto Hanto, Japan, earthquake: Potential involvement of a deep fluid reservoir, Geophys. Res. Lett., 38, L06306, doi:10.1029/2010GL046413, 2011.

Lockner, D. A., J. D. Byerlee, V. Kuksenko, A. Ponomarev, and A. Sidrin, in Fault Mechanics and Transport Properties of Rocks, edited by B. Evans, T.-F. Wong, pp. 3-31, Academic Press, San Diego, CA, 1992.

Omori, F, Note on the preliminary tremor of earthquake motion, J. College Sci, Imperial Univ. Tokyo, 11, 147-159, 1899.

Sakai, S., A. Kato, T. Iidaka, T. Iwasaki, E. Kurashimo, T. Igarashi, N. Hirata, T. Kanazawa, and the group for the joint aftershock observation of the 2007 Noto Hanto Earthquake, Highly resolved distribution of aftershocks of the 2007 Noto Hanto Earthquake by a dense seismic observation, Earth Planets Space, 60, 83-88, 2008.

Scholz, C. H., Microfracturing and the inelastic deformation of rock in compression, J. Geophys. Res., 73, 1417-1432, 1968.

Takanami, T., and G. Kitagawa, in Methods and Applications of Signal Processing in Seismic Network Operations (Lecture Notes in Earth Sciences; 98), 266 pp., Springer-Verlag, Berlin, 2002.

Wessel, P. and W. H. F. Smith, New, improved version of the Generic Mapping Tools Released, Eos Trans. AGU, 79, 579, 1998.

Yoshimitsu, N., H. Kawakata, and N. Takahashi, Broadband P waves transmitting through fracturing Westerly granite before and after the peak stress under a triaxial compressive condition, Earth Planets Space, 61(6), e21-e24, 2009.

I. Doi (e-mail: doi.issei.5e@kyoto-u.ac.jp) and H. Kawakata 